\title{
Implementation of a Pharmacist-Led Inpatient Tobacco Cessation Intervention in a Rehabilitation Hospital: A Before-and-After Pilot Study
}

\author{
Vivian W Li, James Lam, Pam Heise, Robert D Reid, and Kerri A Mullen
}

\begin{abstract}
Background: Inpatient rehabilitation presents a unique opportunity for smoking interventions, given the typical lengths of stay, the relevance of smoking to the admission diagnosis of many patients, and the occurrence of nicotine withdrawal during the hospital stay.
\end{abstract}

Objective: To evaluate the feasibility of implementing a pharmacist-led version of the Ottawa Model for Smoking Cessation (OMSC) program at a rehabilitation hospital, using the indicators of reach, effectiveness, adoption, and implementation.

Methods: A before-and-after pilot study was conducted. Smoking cessation data were collected from 2 cohorts of eligible smokers identified during 4-month periods before (control) and after (intervention) implementation of the OMSC program. Control participants received usual care (i.e., no cessation intervention). Intervention participants received initial in-hospital smoking cessation support (counselling and nicotine replacement therapy), inpatient follow-up during the hospital stay, and 3 months of postdischarge follow-up calls, with all aspects led by hospital pharmacists.

Results: Among all patients admitted to participating inpatient rehabilitation units during the 2 study periods, smoking prevalence was $7.8 \%$ (127/1626). After exclusions, deaths, and withdrawals, 111 patients were retained for analysis: 55 in the control group and 56 in the intervention group. The overall mean age of participants was 64.9 (standard deviation [SD] 14.3) years, with a mean smoking history of 35.0 (SD 24.8) pack-years. There were no significant differences between groups in terms of baseline characteristics. Self-reported abstinence rates (determined 3 months after discharge) were higher after compared with before implementation of the OMSC program: for continuous abstinence, $16 / 56(28.6 \%)$ versus $9 / 55(16.4 \%), \chi^{2}=4.462, p=0.035$; for 7 -day point prevalence abstinence, $21 / 56(37.5 \%)$ versus $10 / 55$ (18.2\%), $\chi^{2}=6.807, p=0.009$.

Conclusions: Implementation of the OMSC program at a large rehabilitation hospital was feasible and led to an increase in 3-month smoking abstinence. This study provides preliminary evidence to support inclusion of smoking interventions as part of inpatient rehabilitation care.

\section{RÉSUMÉ}

Contexte : La réadaptation des patients hospitalisés représente une occasion unique de procéder à des interventions de désaccoutumance du tabac, notamment en raison de la durée habituelle des séjours, du rapport entre le tabagisme et le diagnostic posé à l'admission, et de la survenue du syndrome de sevrage de la nicotine durant le séjour.

Objectif : Étudier la possibilité de mettre en œuvre une version dirigée par des pharmaciens du programme Modèle d'Ottawa pour l'abandon du tabac (MOAT) dans un centre de réadaptation en employant les indicateurs pour la portée, l'efficacité, l'adoption et la mise en œuvre.

Méthodes : Une étude pilote avant-après a été menée. Des données sur la désaccoutumance ont été recueillies auprès de deux cohortes de fumeurs admissibles qui ont été repérés pendant des périodes de quatre mois avant (groupe témoin) et après (groupe expérimental) la mise en œuvre du programme du MOAT. Les participants du groupe témoin ont reçu les soins habituels (c.-à-d. sans intervention de désaccoutumance). Les participants du groupe expérimental ont reçu un soutien initial à l'hôpital pour la désaccoutumance du tabac (des conseils et un traitement de remplacement de la nicotine), un suivi pendant le séjour à l'hôpital, et des appels de suivi pendant les trois mois suivant le congé, le tout sous la direction de pharmaciens d'hôpitaux.

Résultats : Parmi l'ensemble des patients admis dans les unités de réadaptation participantes au cours des deux périodes de l'étude, la prévalence du tabagisme était de 7,8 \% (127/1626). Mis à part les exclusions, les décès et les abandons, 111 patients ont été retenus pour l'analyse : 55 dans le groupe témoin et 56 dans le groupe expérimental. Lâge moyen des participants était de 64,9 (écart-type de 14,3) ans et leur antécédent de tabagisme moyen était de 35,0 (écart-type de 24,8) paquets-années. Aucune différence significative n’a été relevée entre les groupes en ce qui touche aux caractéristiques de base. Les taux d'abstinence autodéclarée (déterminée 3 mois après le congé) étaient plus élevés après la mise en ouvre du programme du MOAT : pour une abstinence continue, $16 / 56(28,6 \%)$ contre $9 / 55(16,4 \%), \chi^{2}=4,462$, $p=0,035$; pour une abstinence ponctuelle de sept jours consécutifs, $21 / 56$ $(37,5 \%)$ contre $10 / 55(18,2 \%), \chi^{2}=6,807, p=0,009$.

Conclusions : La mise en œuvre du programme du MOAT dans un important centre de réadaptation a été possible et a mené à une 
Keywords: smoking cessation, rehabilitation hospital, Ottawa Model for Smoking Cessation, pharmacist

Can J Hosp Pharm. 2018;71(3):180-6 amélioration de l'abstinence du tabac à trois mois. Cette étude donne des résultats préliminaires en appui à l'inclusion d'interventions de désaccoutumance du tabac aux soins de réadaptation de patients hospitalisés.

Mots clés : désaccoutumance du tabac, centre de réadaptation, Modèle d'Ottawa pour l'abandon du tabac, pharmacien

\section{INTRODUCTION}

moking rates have been decreasing over the past 50 years in Canada, but smoking tobacco is still the number 1 preventable cause of morbidity and mortality. ${ }^{1}$ In April 2011, the Ontario government renewed its commitment to building a smoke-free Ontario, which included strategies to expand smoking cessation services in health care settings. ${ }^{2}$ With the mandated implementation of smoke-free policies in hospitals, the availability of smoking cessation services for hospitalized patients is becoming increasingly important. ${ }^{3}$

For various reasons, inpatient rehabilitation settings provide unique opportunities for smoking intervention and prevention of relapse: most smokers temporarily abstain from tobacco before rehabilitation because of the smoke-free policies that are in effect in acute care hospitals; stroke and other medical crises caused by the health risks associated with cigarette smoking can trigger quit attempts; patients in rehabilitation programs are generally in stable health, which facilitates their participation in cessation programs; and an extended stay in a rehabilitation centre permits intensive and repeated tobacco intervention. ${ }^{4,5}$ Moreover, the pooled results from published studies on cessation interventions in rehabilitation hospitals have demonstrated significant increases in smoking cessation rates. $^{5}$

The Ottawa Model for Smoking Cessation (OMSC) is a well-documented cessation model that provides a systematic approach to delivering an evidence-based intervention for tobacco dependence to hospitalized patients. ${ }^{6-8}$ The OMSC program, which has been implemented in various hospitals across Canada, has to date been led primarily by nurses or respiratory therapists. ${ }^{6-8}$ Pharmacist-led interventions have been shown to be feasible and efficacious in community and ambulatory settings, but results in hospital settings have been mixed. ${ }^{9-12}$ To the authors' knowledge, no studies to date have evaluated pharmacist-led smoking cessation programs in rehabilitation centres.

The primary objective of this before-and-after pilot study was to evaluate the feasibility of implementing a pharmacist-led smoking cessation program at a rehabilitation hospital using the RE-AIM framework. ${ }^{13}$

\section{METHODS}

\section{Setting}

This study was conducted at Providence Healthcare, a large rehabilitation hospital in Toronto, Ontario, with 7 clinical units and an annual admission rate of 2780 patients in $2015 / 16 .{ }^{14}$ This hospital provides transition-of-care rehabilitation services between acute care and home for adults of all ages after stroke, orthopedic surgery, lower limb amputation, and other complex medical conditions generally associated with aging. In 2015/16, the average length of stay for inpatients was 29 days. ${ }^{14}$ No formal smoking cessation program existed at the hospital before this study was undertaken.

\section{Study Population}

All smokers admitted to the inpatient rehabilitation units (i.e., those self-reporting any tobacco use in the past 6 months) were considered for participation. Patients were excluded if they died during the hospital stay, were receiving palliative care, were transferred to another hospital, or did not speak English. The research was conducted in accordance with the ethical standards of the Providence Healthcare Research Ethics Board (which also approved the study procedures) and the principles set forth in the Helsinki Declaration. All participants read and signed a consent form that had been approved by the Research Ethics Board (Study File no. 2014-013-1501).

\section{Study Design}

A before-and-after study was conducted to evaluate the impact of a pharmacist-led smoking cessation program in a rehabilitation setting. Pre-intervention data were collected over the 4 months before the program was launched (from April 1 to July 31, 2015). The control group consisted of all smokers identified during this period who were agreeable to an evaluation call 3 months after discharge. This control group received "usual care" as regards smoking cessation (i.e., no cessation intervention). Post-implementation data were collected for 4 months following the program launch (from August 1 to November 30, 2015). The 
intervention group consisted of all smokers identified during this period who were agreeable to an evaluation call 3 months after discharge. Intervention participants received in-hospital smoking cessation support (counselling and nicotine replacement therapy [NRT]), follow-up during the hospital stay, and 3 months of postdischarge follow-up calls.

\section{Ottawa Model for Smoking Cessation Program}

The OMSC's "10 Best Practices for Hospital-Initiated Smoking Cessation Interventions" ${ }^{15}$ were used to guide smoking cessation intervention practices within the hospital. In preparation for the program launch, a smoking cessation task force was formed to facilitate training of clinical staff, to create standardized clinical tools, to develop protocols for smoking cessation strategies, and to add all first-line smoking cessation medications to the pharmacy formulary. All front-line clinical staff received mandatory training about the OMSC program, and clinical pharmacists received additional training on tobacco-dependence interventions. A dedicated pharmacist specialist (V.W.L.), who had been trained as a Certified Tobacco Educator, was hired on a part-time basis ( 2 days/week) to facilitate implementation and delivery of the program.

The smoking cessation program was introduced on all participating clinical units on August 1, 2015. The unit pharmacists screened all new admissions for smoking status and documented patients' responses on the admission order form. The dedicated pharmacist specialist delivered the cessation intervention at the bedside using a standardized smoking consultation form, which was based on the 5A's framework: Ask (for smoking history), Advise (patient to quit), Assess (readiness to quit), Assist (by providing counselling and pharmacotherapies), and Arrange (follow-up, in person or by telephone). ${ }^{16}$ Patients who agreed to scheduled follow-up after discharge received up to 5 live calls (on days 3,14, 30, 60, and 90 after discharge). A standardized follow-up consult form was used to guide patient counselling with regard to quitting. Those who wished to use NRT at home purchased their own supply. Patients were provided with community resources for smoking cessation support beyond the 3-month postdischarge date.

\section{Outcome Measures}

The RE-AIM framework ${ }^{13}$ guided evaluation of the overall public health impact of the program. Of the 5 components of this framework (reach, effectiveness, adoption, implementation, and maintenance), only the first 4 were used to evaluate this project. The fifth component will be considered in future research.

Reach was assessed by means of the following recruitment variables: prevalence of smoking among all admitted patients, proportion of smokers eligible for the study, proportion of smokers recruited to participate in the study, proportion of smokers who withdrew consent to participate during study follow-up, proportion of participants who died, and proportion of participants who were lost to follow-up.

Effectiveness was examined by comparing self-reported continuous and 7-day point prevalence abstinence rates, determined 3 months after discharge, between the control and intervention groups. Participants in both groups were contacted by telephone at 3 months after discharge and asked to respond "yes" or "no" to the following 2 questions: Have you smoked any form of tobacco in the past 3 months? Have you used any form of tobacco in the past 7 days? An intention-to-treat principle was used, whereby, for the purposes of this analysis, participants who were lost to follow-up were considered to be smoking, as per the Russell standard. ${ }^{17}$

Adoption was measured as the proportion of all possible hospital units that implemented the program.

Finally, the indicators of implementation were the proportion of possible smoking cessation consultations that were completed, the proportion of intervention participants who received smoking cessation pharmacotherapies, and the proportion of intervention participants who were enrolled in telephone follow-up counselling upon hospital discharge.

\section{Statistical Analysis}

Analyses were performed with IBM SPSS Statistics 24 software (IBM, Armonk, New York). Participant characteristics were summarized using $t$ tests for continuous variables and $\chi^{2}$ tests for categorical variables. Program efficacy was assessed by comparing unadjusted and adjusted 3-month abstinence rates between groups using binary logistic regression. The following variables were included in the adjusted models: age, sex, number of cigarettes smoked per day at baseline, length of stay in the hospital, and whether or not the primary admitting diagnosis was smoking-related (i.e., related to cancer, a chronic lung condition, cardiovascular or peripheral vascular disease, or stroke). ${ }^{18}$

\section{RESULTS}

\section{Reach}

During the pre-intervention data collection period, 812 patients were admitted, of whom 62 were smokers, for a smoking prevalence of $7.6 \%$. Of these 62 pre-intervention smokers, $2(3.2 \%)$ did not meet the inclusion criteria because of inability to communicate in English, and 2 (3.2\%) declined participation (Figure 1). Therefore, 58 (93.5\%) of the initial 62 smokers were recruited into the control group. Over the 3-month follow-up period, $3(5.2 \%)$ of these control participants died. As a result, $55(94.8 \%)$ of participants in the control group were eligible for the 3-month postdischarge evaluation.

During the post-intervention data collection period, 814 patients were admitted, of whom 65 were smokers, for a smoking 


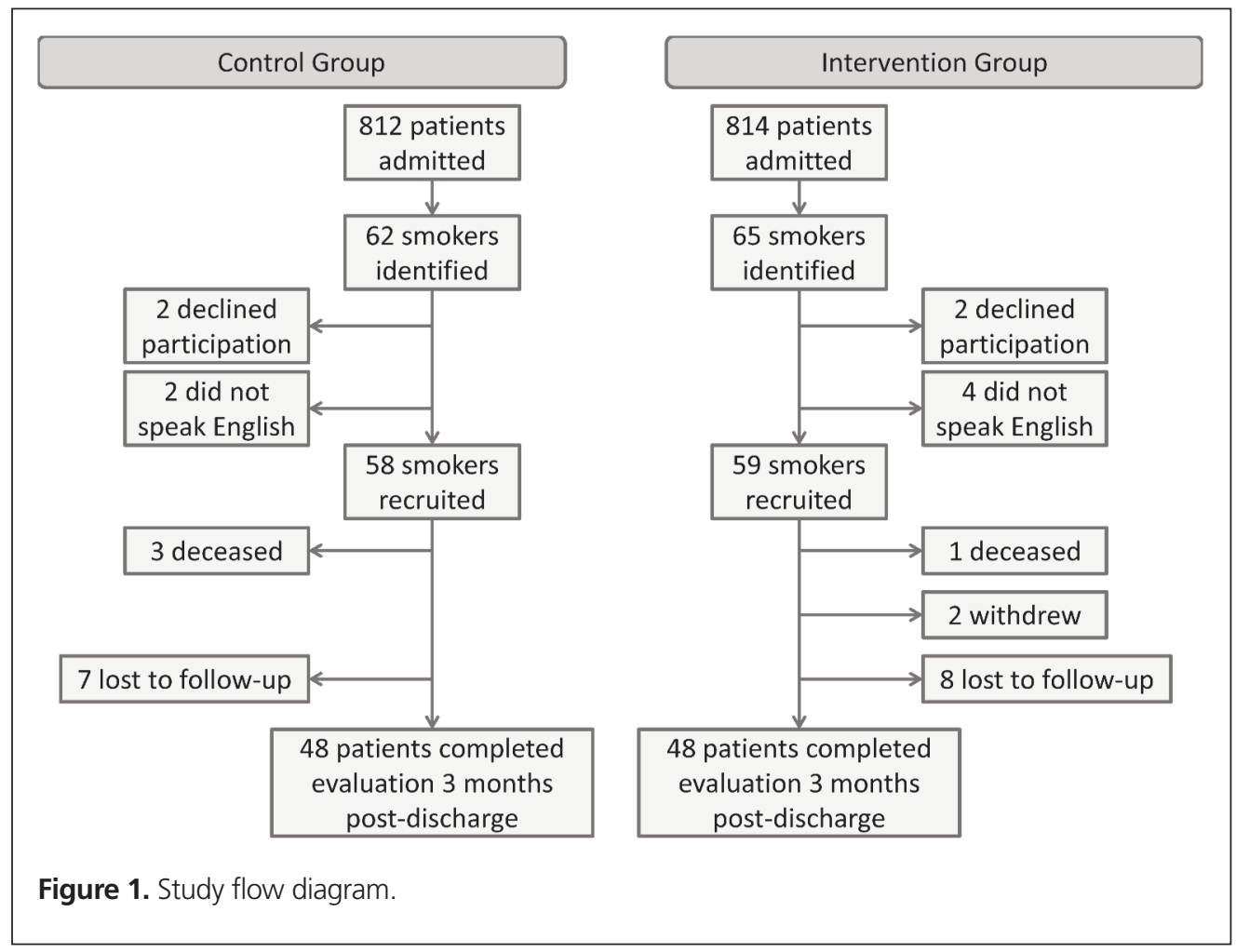

prevalence of $8.0 \%$. Of these 65 post-intervention smokers, $4(6.2 \%)$ did not meet the inclusion criteria because of inability to communicate in English, and $2(3.1 \%)$ declined to participate in the study. Therefore, 59 (90.8\%) of the initial 65 smokers were recruited into the intervention group and received the intervention. Over the 3-month intervention follow-up period, 1 participant (1.7\%) died and 2 participants (3.4\%) withdrew consent for follow-up evaluation. As a result, $56(94.9 \%)$ of participants in the intervention group were eligible for the 3 -month postdischarge evaluation.

Seven $(12.7 \%)$ of the 55 participants in the control group and $8(14.3 \%)$ of the 56 participants in the intervention group could not be reached for the 3-month postdischarge evaluation. For the purposes of the intention-to-treat analysis, these participants were considered to be current smokers. ${ }^{17}$

\section{Participant Characteristics}

There were no significant differences between groups in terms of baseline characteristics (Table 1). Overall, the mean age of participants was 64.9 (standard deviation [SD] 14.3) years, and more than half of the smokers were male $(65 / 111,58.6 \%)$. Participants had long smoking histories, with a mean of 35.0 (SD 24.8) pack-years and an average 17.9 (SD 13.1) cigarettes smoked per day. Forty-eight (43.2\%) of the participants were admitted for rehabilitation because of a smoking-related illness. ${ }^{18}$ The median number of days since the person's last cigarette, as reported at the time of admission, was 7 (range 0.04-90) for the control group and 10 (range 0.04-135) for the interven- tion group. The median length of stay in hospital was 23 (range 6-159) days for the control group and 23 (range 7-79) days for the intervention group.

\section{Effectiveness}

Self-reported abstinence rates, determined 3 months after discharge and adjusted for baseline characteristics, were higher after than before implementation of the OMSC program (Figure 2). For continuous abstinence, the rates were $28.6 \%(16 / 56)$ in the intervention group and $16.4 \%(9 / 55)$ in the control group $\left(\chi^{2}=4.462, p=0.035\right)$; for 7-day point prevalence abstinence, the rates were $37.5 \%(21 / 56)$ in the intervention group and $18.2 \%(10 / 55)$ in the control group $\left(\chi^{2}=6.807, p=0.009\right)$. Participants who died were excluded from the analyses, and those lost to follow-up were counted as smokers. ${ }^{17}$

\section{Adoption}

Six (86\%) of the 7 hospital units adopted the smoking cessation program, The sole exception was the palliative care unit, because palliative care was one of the exclusion criteria. Routine identification of patients who smoked and referral to the smoking cessation program were incorporated into usual hospital practice.

\section{Implementation}

The standardized smoking cessation consultation forms were completed for $90.8 \%$ (59/65) of smokers identified in the 4 months after OMSC implementation. All participating patients 
This single copy is for your personal, non-commercial use only.

For permission to reprint multiple copies or to order presentation-ready copies for distribution, contact CJHP at publications@cshp.ca

Table 1. Baseline Characteristics of Study Participtants

\begin{tabular}{|c|c|c|c|c|c|}
\hline Characteristic & $\begin{array}{l}\text { Overall } \\
(n=111)\end{array}$ & $\begin{array}{l}\text { Control } \\
(n=55)\end{array}$ & $\begin{array}{l}\text { Intervention } \\
\quad(n=56)\end{array}$ & Test Statistic & $p$ Value \\
\hline Mean age (years) $\pm S D$ & $64.9 \pm 14.3$ & $64.5 \pm 14.1$ & $65.3 \pm 14.5$ & $\begin{array}{l}t=-0.30 \\
d f=109\end{array}$ & 0.77 \\
\hline$\overline{\text { Mean no. of cigarettes/day } \pm \text { SD }}$ & $17.9 \pm 13.1$ & $18.8 \pm 13.3$ & $17.0 \pm 13.0$ & $\begin{array}{l}t=0.72 \\
d f=106\end{array}$ & 0.48 \\
\hline Sex, no. (\%) male & $65(58.6)$ & $34(61.8)$ & $31(55.4)$ & $\begin{array}{c}\chi^{2}=0.48 \\
d f=1\end{array}$ & 0.49 \\
\hline $\begin{array}{l}\text { No. (\%) with smoking-related } \\
\text { admission diagnosis* }\end{array}$ & $48(43.2)$ & $28(50.9)$ & $20(35.7)$ & $\begin{array}{c}\chi^{2}=2.61 \\
d f=1\end{array}$ & 0.11 \\
\hline $\begin{array}{l}\text { Median time since last cigarette } \\
\text { and range (days) }\end{array}$ & $8(0.04-135)$ & $7(0.04-90)$ & $10(0.04-135)$ & $F=1.02$ & 0.32 \\
\hline $\begin{array}{l}\text { Median hospital length of stay } \\
\text { and range (days) }\end{array}$ & $23(6-159)$ & $23(6-159)$ & $23(7-79)$ & $F=1.75$ & 0.19 \\
\hline
\end{tabular}

SD = standard deviation

*The following admission diagnoses were classified as smoking-related: neoplasm or cancer-related, cardiovascular disease (including acute coronary syndrome and heart failure), stroke, respiratory condition (including chronic obstructive pulmonary disorders and bronchitis), and limb amputation for peripheral vascular disease.

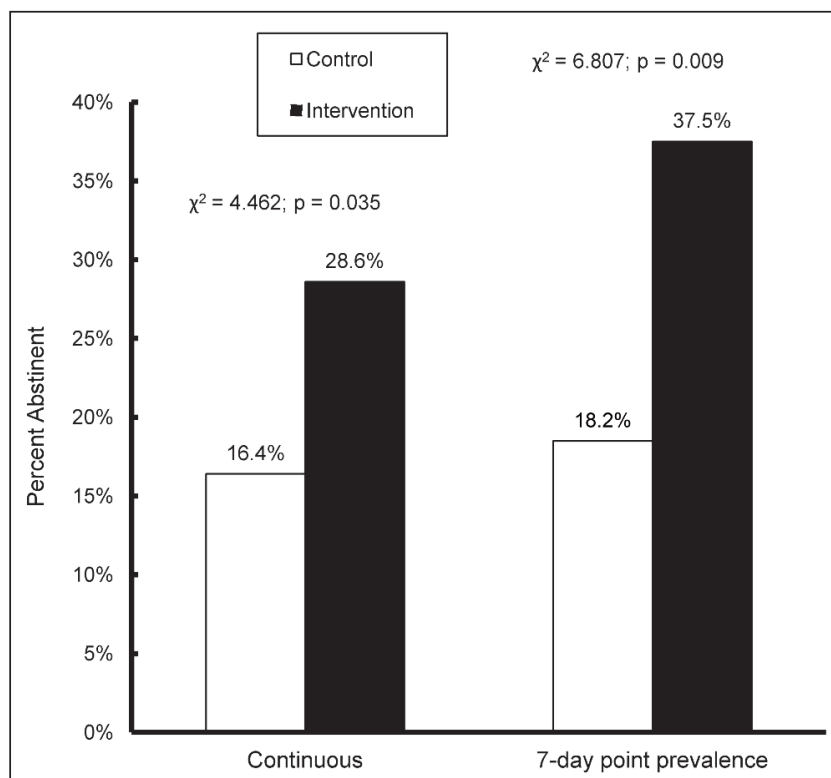

Figure 2. Smoking abstinence rates (continuous and 7-day point prevalence), as reported by participants 3 months after discharge from the rehabilitation hospital.

received a structured, brief counselling session during completion of the consultation. Each consultation lasted 30 to $40 \mathrm{~min}$, and inpatient follow-up ranged from 20 to $30 \mathrm{~min}$. Overall, NRT was prescribed to $71.2 \%(42 / 59)$ of the intervention group during the hospital stay; other smoking cessation medications were available but not utilized. In addition, NRT was used after discharge by $28.6 \%(16 / 56)$ of patients in the intervention group. Among participants in the intervention group, the majority $(40 / 56$, $71.4 \%$ ) were ready to quit at the time of dischange and received the scheduled telephone follow-up. Those who declined scheduled follow-up calls either felt they had already quit while in hospital (and thus did not require follow-up calls) or did not wish to quit. Each follow-up telephone call took 10 to $20 \mathrm{~min}$.

\section{DISCUSSION}

This study demonstrated the feasibility of implementing a pharmacist-led smoking cessation intervention in a rehabilitation hospital. Following implementation of the OMSC program, pharmacists provided smoking cessation interventions to more than $90 \%$ of admitted smokers, which led to high uptake of both in-hospital NRT and follow-up support after discharge. Over the short term (i.e., at 3 months after discharge), participants in the intervention group showed higher rates of smoking abstinence than those in the control group.

A meta-analysis of results from 9 OMSC hospital sites in Ontario, most of which used a nurse-led intervention, showed that in-hospital NRT use ranged from 6\% to 58\%; in contrast, the pharmacist-led intervention in the current study resulted in $71.2 \%$ of patients using NRT during their hospital stay for the purposes of nicotine withdrawal management and smoking cessation. ${ }^{6}$ It is possible that the longer lengths of stay among patients in a rehabilitation hospital (relative to acute care hospitals) led to greater use of NRT to manage the discomfort of nicotine withdrawal. It is also possible that pharmacists are more likely than other health care professionals to recommend NRT to patients who smoke, because of their knowledge about and comfort in using and managing the relevant medication. The proportion of patients who used NRT at home (after discharge) dropped to $28.6 \%$. It is possible that patients had less need for NRT at home following prolonged abstinence during the hospital stay. The cost of NRT may have also contributed to low utilization of NRT after discharge. Future research should investigate whether providing free NRT to patients after hospitalization has positive effects on the cessation rate.

Two-thirds of the participants enrolled in postdischarge follow-up, a rate much higher than reported in evaluations of the OMSC program in general hospitals ( $8 \%$ to $32 \%){ }^{6,7}$ Participants in the current study received live calls from the pharmacist 
specialist, a person whom they had met during their initial consultations. More commonly, follow-up offered by hospitals using the OMSC intervention begins with automated telephone calls that are monitored by nurse counsellors, who are different from the nurses with whom patients originally spoke while in hospital. Only patients who indicate during the automated calls that they are struggling with cessation receive a call-back from a nurse counsellor. It is possible that patients prefer follow-up from a health professional whom they have met in person. The $12.2 \%$ absolute improvement in 3-month continuous postdischarge cessation rate was similar to that observed in previous evaluations of other inpatient smoking cessation programs adapted from the OMSC program, in which 6-month absolute improvements in cessation rates ranged from $11 \%$ to $15 \% .6,7,14$

To the authors' knowledge, this is the first investigation of a pharmacist-led smoking cessation program in a rehabilitation hospital. The results obtained here were positive, in contrast to the negative results obtained in a previous study of pharmacistled smoking cessation at tertiary care hospitals. ${ }^{11}$ It is possible that pharmacists in rehabilitation settings have more opportunities to engage smokers and optimize the use of NRT. Because the majority of admissions to the rehabilitation hospital came from smoke-free acute care hospitals, the pharmacist-led interventions in this study focused on managing nicotine withdrawal symptoms and maintaining continued abstinence during hospitalization. Differences in cessation management in rehabilitation hospitals may also have affected the study results. Two key facilitators of program implementation in the current study were (1) the presence of an existing hospital protocol, whereby a full-time unit pharmacist was available to screen smoking status of new admissions on each unit, and (2) the use of a dedicated specialist pharmacist (2 days/week) to provide the tobacco-dependence interventions. Expansions in scope of practice for pharmacists in Ontario have encouraged the profession to shift toward providing smoking cessation interventions as part of clinical practices. ${ }^{19}$ This study demonstrated the feasibility of having pharmacists lead a smoking cessation initiative in an inpatient rehabilitation setting.

This pilot study had several limitations. The sample was small because of the low prevalence of smoking among patients admitted to the study institution and the limited recruitment period. However, we did collect important recruitment and effectiveness data that will support planning for a larger trial. There was no biochemical verification of smoking abstinence at follow-up, so these data relied completely on self-reporting. ${ }^{6}$ Smoking cessation was evaluated only once, 3 months after discharge; therefore, we cannot draw inferences about the longterm effects of the cessation program. However, as part of this pilot program, patients were informed about community resources to support smoking cessation beyond 3 months, and these may contribute to long-term smoking cessation outcomes. In addition to determining long-term outcomes, future studies should examine the impact of hospital-based smoking cessation interventions on in-hospital smoking cessation and on health and health care outcomes, including recovery, healing, procedure complications, and length of stay. Evaluation of the sustainability of the cessation program was not assessed in the current study.

\section{CONCLUSION}

Implementation of a pharmacist-led OMSC program at the study rehabilitation hospital was feasible and led to an increase in 3 -month smoking abstinence rates. This study provides preliminary evidence to support the inclusion of smoking interventions as part of inpatient rehabilitation care, both to ensure patient comfort and safety and to improve patient outcomes.

\section{References}

1. Reid JL, Hammond D, Rynard VL, Madill CL, Burkhalter R. Tobacco use in Canada: patterns and trends, 2017 edition. Waterloo (ON): University of Waterloo, Propel Centre for Population Health Impact; 2017.

2. Building on our gains, taking action now: Ontario's Tobacco Control Strategy for 2011-2016. Toronto (ON): Tobacco Strategy Advisory Group; 2010 Oct 18 [cited 2016 Jan]. Available from: http://otru.org/wp-content/uploads/ 2012/06/TSAGReport.pdf

3. CAN-ADAPTT's Clinical Practice Guideline Development Group. Specific populations: hospital-based populations. Toronto (ON): Centre for Addiction and Mental Health; 2011 Mar 31 [cited 2016 Jan]. Available from: https://www.nicotinedependenceclinic.com/English/CANADAPTT/ Documents/Guideline/Hospital\%20Based\%20Populations.pdf

4. Guilmette TJ, Motta SI, Shadel WG, Mukand J, Niaura R. The prevalence of cigarette smoking in an acute inpatient physical medicine and rehabilitation population. Subst Abus. 2001;22(3):187-92.

5. Rigotti NA, Clair C, Munafo MR, Stead LF. Interventions for smoking cessation in hospitalised patients. Cochrane Database Syst Rev. 2012;5: CD001837.

6. Reid RD, Mullen KA, D’Angelo MES, Aitken DA, Papadakis S, Haley PM, et al. Smoking cessation for hospitalized smokers: an evaluation of the “Ottawa model”. Nicotine Tob Res. 2010;12(1):11-8.

7. Mullen KA, Manual DG, Hawken SJ, Pipe AL, Coyle D, Hobler LA, et al. Effectiveness of a hospital-initiated smoking cessation programme: 2-year health and healthcare outcomes. Tob Control. 2017;26(3):293-9.

8. Reid RD, Pipe AL, Quinlan B. Promoting smoking cessation during hospitalization for coronary artery disease. Can J Cardiol. 2006;22(9):775-80.

9. Sinclair HK, Bond CM, Stead LF. Community pharmacy personnel interventions for smoking cessation. Cochrane Database Syst Rev. 2004;1: CD003698.

10. Dent LA, Harris KJ, Noonan CW. Tobacco interventions delivered by pharmacists: a summary and systematic review. Pharmacotherapy. 2007; 27(7):1040-51.

11. Thomas D, Abramson MJ, Bonevski B, Taylor S, Poole SG, Paul E, et al. Integrating smoking cessation into routine care in hospitals - a randomized controlled trial. Addiction. 2016;111(4):714-23.

12. Dobrinas M, Blanc AL, Rouiller F, Christen G, Coronado M, Tagan D, et al. Clinical pharmacist's role in implementing a smoking cessation intervention in a Swiss regional hospital: an exploratory study. Int J Clin Pharm. 2014;36(3):526-34.

13. Glasgow RE, Vogt TM, Boles SM. Evaluating the public health impact of health promotion interventions: the RE-AIM framework. Am J Public Health. 1999;89(9):1322-7. 
14. Providence Healthcare 2015-16 annual report. Toronto (ON): Providence Healthcare.; 2016 [cited 2017 Jan]. Available from: www.providence.on.ca/ Uploads/2015-2016\%20Annual\%20Report/files/assets/basic-html/ index.html\#1

15. Reid R, Mullen KA, Pipe A. Hospital-initiated smoking cessation. In: Els C, Kunyk D, Selby P, editors. Disease interrupted: a clinical guide to tobacco reduction and cessation. 2 nd ed. Toronto $(\mathrm{ON})$ : Centre for Addiction and Mental Health; 2017. p. 329-39.

16. Lawson PJ, Flocke SA, Casucci B. Development of an instrument to document the 5A's for smoking cessation. Am J Prev Med. 2009;37(3):248-54.

17. West R, Hajek P, Stead L, Stapleton J. Outcome criteria in smoking cessation trials: proposal for a common standard. Addiction. 2005;100(3):299-303.

18. The health consequences of smoking - 50 years of progress. A report of the Surgeon General. Atlanta (GA): US Department of Health and Human Services, Centers for Disease Control and Prevention, National Center for Chronic Disease Prevention and Health Promotion, Office on Smoking and Health; 2014 [cited 2016 Jan]. Available from: www.surgeongeneral.gov/library/ reports/50-years-of-progress/index.html

19. Pharmacy smoking cessation program - the pharmacist's role in a smoking cessation system. Toronto (ON): Ontario Ministry of Health and Long-Term Care; 2014 Aug 11 [cited 2017 Jan]. Available from: www.health.gov.on.ca/ en/pro/programs/drugs/smoking
Vivian W Li, BSC, BPharm, RPh, CTE, is with Providence Healthcare Hospital, Scarborough, Ontario.

James Lam, BSPharm, RPh, is with Providence Healthcare Hospital, Scarborough, Ontario.

Pam Heise, HBA Kin, BSW, MSW, is with Prevention and Cardiac Rehabilitation, University of Ottawa Heart Institute, Ottawa, Ontario.

Robert D Reid, MBA, PhD, is with Prevention and Cardiac Rehabilitation, University of Ottawa Heart Institute, Ottawa, Ontario.

Kerri A Mullen, HBA Kin, MSc, PhD, is with Prevention and Cardiac Rehabilitation, University of Ottawa Heart Institute, Ottawa, Ontario.

Competing interests: Kerri A Mullen and Robert D Reid are named developers of the Ottawa Model for Smoking Cessation, a registered trademark of the University of Ottawa Heart Institute. Robert Reid has received personal fees from Johnson \& Johnson Inc and from Pfizer Inc, as well as grants from Pfizer Global Research Awards, all for activities outside the submitted work. No other competing interests were declared.

\section{Address correspondence to:}

James Lam

Providence Healthcare Hospital

3276 St Clair Avenue East

Scarborough ON M1L 1W1

e-mail: jlam@providence.on.ca

Funding: This study was supported by research funds from Providence Healthcare Hospital (Study File no. 2014-013-1501). The University of Ottawa Heart Institute provided nonfinancial support for implementation of the Ottawa Model for Smoking Cessation as described in this study. 